\title{
MUDAS DE Physalis pubescens L. PROPAGADAS POR DIFERENTES MÉTODOS E SUBSTRATOS
}

\section{SEEDLINGS OF PLANTS OF Physalis pubescens L. PROPAGATED BY DIFFERENT METHODS AND SUBSTRATES}

\author{
Douglas Alvarez ALAMINO ${ }^{1}$ \\ Marisa de Cacia OLIVEIRA ${ }^{2}$
}

\begin{abstract}
RESUMO
O presente trabalho teve por objetivo avaliar a relação entre métodos de propagação e tipo de substrato no desenvolvimento de plantas de Physalis pubescens L., onde foram avaliadas plantas produzidas a partir de sementes e estacas herbáceas. Como substratos foram empregados os seguintes tratamentos: (SA) Solo + areia; (SV) Solo + vermiculita; (SP) Solo + Plantmax®; (SAV); Solo + areia + vermiculita e (S) Solo. As seguintes variáveis foram analisadas: comprimento da parte aérea e da maior raiz; área foliar; massas fresca e seca das folhas, caules e raízes; volume radicular. $O$ delineamento experimental utilizado foi inteiramente casualizado, em um esquema fatorial de 2x5 (método x substrato), com 10 repetições por tratamento. Observou-se interação significativa entre os fatores para massas fresca e seca dos caules, com destaque para o método estaquia e os substratos SA, SP e S. Para o comprimento da parte aérea e da maior raiz, a propagação por estaquia foi superior à via seminífera, ao contrário da área foliar, massa fresca e seca de folhas e raízes, que não apresentaram diferenças significativas. Quanto aos substratos, não houve diferença significativa para nenhuma das variáveis citadas anteriormente. Portanto, concluiu-se que a utilização da estaquia com qualquer um dos substratos empregados, em condições controladas, é mais eficiente na produção de mudas se comparado à produção por sementes.
\end{abstract}

Palavras chave: camapu; semente; estaquia.

\section{ABSTRACT}

This study aimed to evaluate the relationship between different methods of propagation and types of substrates in the development of Physalis pubescens L., by evaluating plants produced from seeds and herbaceous cuttings. The materials used as substrate in different combinations were: (SA) soil + sand; (SV) soil + vermiculite; (SP) soil + Plantmax®; (SAV); soil + sand + vermiculite and (S) soil. The variables analyzed were: length of the aerial part and of the largest root; leaf area; fresh and dry weight of leaves, stems and roots; and root volume. The experimental design used was the completely randomized in factorial scheme $2 \times 5$ (method $x$ substrate), with 10 repetitions per treatment. Significant interaction was observed between fresh and dry mass of stems, highlighting the cutting method, using SA, SP and S as substrates. Propagation of $P$. pubescens by stem cuttings was superior to the seed method considering the length of aerial parts and roots, unlike the fresh and dry mass of leaves and roots that had no significant differences. On the other hand, the substrates had no significant effect on any of the evaluated variables. In conclusion, the stem cutting method combined with any of the substrate can be used, under controlled conditions, to propagate $P$. pubescens, being this method more effective than the seed propagation.

Key words: camapu; seed; stem cutting.

${ }^{1}$ Biólogo, Mestrando do Programa de Pós Graduação em Agronomia da UniversidadeTecnológica Federal do Paraná, Pato Branco, PR, Brasil Bolsista do CNPq. Email: doug_biologo_@hotmail.com

${ }^{2}$ Eng. Agrônoma, Doutora, Professora. Universidade Tecnológica Federal do Paraná, Via do Conhecimento, km 01, 85503-390, Pato Branco,

PR, Brasil. Email: mcacia@utfpr.edu.br, 
ALAMINO, D.A. et al. Mudas de Physalis pubescens L. propagadas...

\section{INTRODUÇÃO}

A produção de pequenas frutas, de modo geral, tem se mostrado uma excelente alternativa ao desenvolvimento econômico das pequenas propriedades, caracterizando-se como uma atividade com baixo custo de implantação e manutenção, boa adaptação às condições socioeconômicas e ambientais, com possibilidades de ser desenvolvida pelo cultivo orgânico (Schneider et al., 2007).

Visando suprir demandas de mercado, muitos produtores têm optado pela produção de uma ampla variedade de espécies, muitas das quais ainda desconhecidas pela grande maioria dos consumidores. Dentre as espécies cultivadas atualmente, estão as do gênero Physalis, com destaque para Physalis peruviana e em menor proporção $P$. angulata e $P$. pubescens (Rufato et al., 2008).

A propagação das espécies citadas anteriormente se dá, em sua maior parte, através da via sexuada, já que estas possuem um elevado percentual de germinação (85-90\%), porém, este não é o único método empregado, já que muitas plantas são propagadas por estaquia e cultura de tecidos, sendo este último método pouco utilizado devido a seu alto custo (Rufato et al., 2008).

Na propagação, seja ela sexuada ou assexuada, em ambientes protegidos, além do solo, outros substratos orgânicos e/ou sintéticos utilizados isoladamente ou em combinação podem resultar em obtenção de maior número de mudas e grau de sanidade elevado. Diferentemente do solo, boa parte dos materiais possibilitam o manejo adequado da água, evitando a umidade excessiva em torno das raízes e o consequente aparecimento de doenças de origem fúngica e/ou bacteriana, além de manter teores adequados de oxigênio para a manutenção destas estruturas (Fernandes \& Corá, 2001).

Assim, como não existe uma combinação universal ou específica ao desenvolvimento de todas as espécies vegetais, é prudente que sejam feitos testes com diferentes matérias, visando iden- tificar o substrato ou a combinação de materiais que satisfaçam com maior eficiência os requisitos fisiológicos e nutricionais de Physalis pubescens L. sem, no entanto, inviabilizar o processo a pequenos produtores.

O presente trabalho teve como objetivo avaliar os aspectos agronômicos em plantas de $P$. pubescens $\mathrm{L}$. obtidas com sementes e estaquia, em diferentes substratos.

\section{MATERIAL E MÉTODOS}

O experimento foi realizado em casa de vegetação localizada na Universidade Tecnológica Federal do Paraná, Campus Pato Branco, no período de 15/10/2009 a 15/02/2010.

Em estudos preliminares foram testados dois tipos de estacas de fisalis (Physalis pubescens. L.): da porção basal e da mediana dos caules de plantas com aproximadamente quatro meses de idade, sendo que as últimas apresentaram $100 \%$ de enraizamento em menor tempo, utilizando-se Plantmax® como substrato. Em função destes resultados, optou-se por esses materiais retirados de plantas matrizes cultivadas a campo e livres de quaisquer sinais de injúrias. As sementes também foram retiradas dos frutos produzidos por essas plantas. $O$ preparo do material vegetal consistiu em um corte na base, em forma de bisel, próximo a uma gema, ficando a estaca com aproximadamente $15 \mathrm{~cm}$. Foi realizada, também, a retirada das folhas remanescentes, deixando-se somente o primeiro e segundo pares de folhas, as quais foram seccionadas ao meio visando, assim, reduzir a superfície transpiratória.

Os substratos utilizados foram: SA (solo + areia / 1:1 v/v); SV (solo + vermiculita / 1:1 v/v); SP (solo + Plantmax $®$ / 1:1 v/v); SAV (solo + areia + vermiculita / 1:1:1 v/v); S (solo). Na Tabela 01 é apresentada a análise química dos respectivos substratos.

Tabela 1 - Análise química dos substratos. UTFPR, Campus Pato Branco, 2011.

\begin{tabular}{|c|c|c|c|c|c|c|c|c|}
\hline & $\begin{array}{c}\text { Matéria } \\
\text { orgânica }\end{array}$ & $\mathrm{P}$ & $\mathrm{K}^{+}$ & $\mathrm{Al}^{+3}$ & $\mathrm{Ca}^{+2}$ & $\mathrm{Mg}^{+2}$ & $\begin{array}{c}\text { Saturação } \\
\text { de bases }\end{array}$ & $\mathrm{pH}$ \\
\hline Substratos* & $\mathrm{g} / \mathrm{dm}^{-3}$ & \multicolumn{2}{|c|}{$--\mathrm{mg} / \mathrm{dm}^{-3}--$} & \multicolumn{3}{|c|}{----- $\mathrm{cmol}_{\mathrm{d}} / \mathrm{dm}^{-3}$} & $\%$ & $\mathrm{CaCl}_{2}$ \\
\hline SA & 30,82 & 5,36 & 84,06 & 0,33 & 3,54 & 1,74 & 44,7 & 4,5 \\
\hline SV & 33,50 & 24,4 & 211,14 & 0,07 & 5,47 & 6,51 & 71,0 & 5,6 \\
\hline SP & 87,11 & 53,51 & 220,91 & 0,07 & 11,92 & 5,26 & 66,0 & 5,0 \\
\hline SAV & 34,17 & 18,23 & 147,27 & 0,22 & 3,93 & 4,49 & 60,1 & 4,9 \\
\hline$S$ & 60,31 & 4,83 & 148,58 & 0,15 & 6,22 & 3,04 & 50,9 & 4,7 \\
\hline
\end{tabular}

* SA (Solo + areia); SV (Solo + vermiculita); SP (Solo + Plantmax®); SAV (Solo + areia + vermiculita); S (Solo). 
ALAMINO, D.A. et al. Mudas de Physalis pubescens L. propagadas...

Os substratos foram acondicionados em vasos de prolipropileno com capacidade para $5 \mathrm{~L}$. As mudas originadas de sementes foram produzidas em bandeja alveolada com Plantmax®, em casa de vegetação e ao atingirem cerca de $10 \mathrm{~cm}$ foram transplantadas para os vasos contendo os respectivos tratamentos. As estacas foram colocadas nos vasos com cerca de $1 / 3$ de seu comprimento coberto pelo substrato.

Os vasos foram mantidos em condições de casa de vegetação, com temperatura controlada $\left(26 \pm 2{ }^{\circ} \mathrm{C}\right)$. A irrigação foi feita por nebulização por $10 \mathrm{~min}$, a cada $12 \mathrm{~h}$ nos primeiros 30 dias. Após este período, a irrigação passou a ser realizada uma vez por dia, e dos 60 dias até o final do experimento, além da nebulização foi realizada rega manual, vaso a vaso, devido ao grande diâmetro das folhas que escoavam a água e não permitiam que a mesma entrasse em contanto com os substratos.

Decorridos 30 dias da implantação do experimento, a altura das plantas passou a ser mensurada quinzenalmente. Aos 60 dias do transplantio e estaquia, foi realizada adubação orgânica com a incorporação de $100 \mathrm{~g}$ de húmus de minhoca por vaso; além disso, deu-se início ao tutoramento das mudas com estacas de madeira. Não foram realizados tratamentos fitossanitários nas plantas durante o experimento a não ser a retirada manual de plantas daninhas.

Aos 120 dias após o plantio nos vasos, foram avaliados os seguintes parâmetros: área foliar $\left(\mathrm{cm}^{2}\right.$ planta $\left.^{-1}\right)$; massas fresca e seca $(\mathrm{g})$ das fo-
Ihas, caules e raízes; comprimento $(\mathrm{cm})$ da maior raiz e volume $(\mathrm{mL})$ radicular, calculado como sendo o volume de água removido pela imersão das raízes em proveta graduada com $2 \mathrm{~L}$ de água em seu interior. As massas secas das folhas, caules e raízes foram obtidas após secagem em estufa com circulação de ar, a temperatura de $60^{\circ} \mathrm{C}$, até massa constante.

O delineamento experimental utilizado foi inteiramente casualizado, em um esquema fatorial de $2 \times 5$, sendo 2 métodos de propagação e 5 substratos, com 10 repetições por tratamento. Todos os dados coletados foram transformados em arcoseno $\sqrt{ } \mathrm{x} / 100$ e submetidos à análise de variância, sendo as médias comparadas pelo teste Tukey a $5 \%$ de significância, com aplicativo ASSISTAT. Para meIhor apresentação, as médias das variáveis transformadas foram reconvertidas e apresentadas na escala original.

\section{RESULTADOS E DISCUSSÃO}

No experimento realizado, foi constatada interação significativa entre os fatores método de propagação e tipo de substrato somente para a variável massa fresca e seca dos caules, onde a propagação através de estacas herbáceas mostrouse estatisticamente superior à propagação por sementes, principalmente para os tratamentos SP (solo + Plantmax®) e S (solo) (Tabela 02).

Tabela 2 - Resultado da interação entre métodos de propagação e substratos para a massa fresca e seca $(\mathrm{g})$ do caule de Physalis pubescens L. UTFPR, Campus Pato Branco, 2011.

\begin{tabular}{lcccc}
\hline \multirow{2}{*}{ Substratos } & \multicolumn{2}{c}{ Massa fresca do caule $(\mathrm{g})$} & Massa seca do caule $(\mathrm{g})$ \\
\cline { 2 - 5 } & Sementes & Estacas & Sementes & Estacas \\
\hline Solo + Areia & $97,69 \mathrm{Ab}$ & $129,27 \mathrm{Aa}$ & $21,83 \mathrm{Ab}$ & $31,10 \mathrm{Aa}$ \\
Solo + Vermiculita & $95,47 \mathrm{Ab}$ & $114,31 \mathrm{Aa}$ & $20,92 \mathrm{Aa}$ & $27,34 \mathrm{Aa}$ \\
Solo + Plantmax® & $82,11 \mathrm{Ab}$ & $124,03 \mathrm{Aa}$ & $16,93 \mathrm{Ab}$ & $25,59 \mathrm{Aa}$ \\
Solo + Areia + Vermiculita & $112,36 \mathrm{Aa}$ & $100,49 \mathrm{Aa}$ & $23,06 \mathrm{Aa}$ & $18,60 \mathrm{Aa}$ \\
Solo & $64,85 \mathrm{Bb}$ & $126,86 \mathrm{Aa}$ & $14,37 \mathrm{Ab}$ & $28,57 \mathrm{Aa}$ \\
\hline CV\% & \multicolumn{3}{c}{10,51} & \\
\hline
\end{tabular}

Médias seguidas por letra maiúscula nas colunas e minúscula nas linhas não diferem entre si, pelo teste de Tukey a $5 \%$ de significância. Dados transformados em $\sqrt{ } \mathrm{x} / 100$.

No caso do método de propagação, o meIhor desempenho da estaquia em relação às plantas produzidas a partir de sementes pode estar relacionado à arquitetura da parte aérea, já que no primeiro caso as plantas apresentaram caules únicos, os quais permaneceram com esta característica durante todo o experimento, contrário ao que foi observado para o segundo método, já que após algumas semanas do transplantio as plantas passaram a apresentar inúmeras brotações adventícias na base, o que sem dúvida obrigou as plantas a disponibilizarem e realocarem água e seus assimilados para estas regiões.

Aliado a arquitetura da parte aérea, a formação de folhas com maior diâmetro nas estacas $(12$ a $15 \mathrm{~cm})$ pode ter sido outro fator favorável ao 


\section{ALAMINO, D.A. et al. Mudas de Physalis pubescens L. propagadas...}

acúmulo eficiente de biomassa nos caules, já que esta característica possibilita às plantas maior área de captação da luz, induzindo-as a realizarem taxas fotossintéticas mais intensas, o que segundo $\mathrm{Ne}$ greiros et al. (2004) faz com que aspectos biométricos como diâmetro e massa fresca de caule e altura média de plantas aumentem consideravelmente.

Em relação aos substratos, esta interação significativa pode estar relacionada à disponibilidade de nutrientes, visto que os maiores teores de matéria orgânica, de fósforo e potássio encontravam-se nos tratamentos SA (solo + areia) e S (solo). Para Oliveira \& Hernandez (2008), ambos são considerados essenciais ao desenvolvimento das plantas por estarem ligados a formação de esqueletos carbônicos, o que garante o acúmulo de biomassa vegetal. Segundo Marschener (1995) e Malavolta (1974) o fósforo absorvido pela planta está diretamente relacionado à fotossíntese, já que faz parte da composição do ATP, aos processos de respiração, degradação de açúcares, armazenamento, transferência e utilização de energia, além de participar da divisão celular, favorecendo o desenvolvimento das plantas como um todo. Assim como o fósforo, o potássio também exerce funções fisiológicas importantes, estando vinculado ao balanço osmótico, controle da abertura e fechamento dos estômatos, fotossíntese, ativação enzimática, síntese de proteínas e transporte de carboidratos (Taiz \& Zeiger, 2004).

Para as variáveis altura da parte aérea, comprimento da maior raiz, aérea foliar, massa fresca e seca das folhas e raízes e volume das raízes, não foram constatadas as mesmas interações encontradas para as variáveis anteriores, indicando que os fatores substrato e método de propagação não exercem influência um sobre o outro. Porém, novamente a propagação por estacas foi superior a por sementes, apresentando valores médios de 123,14 e $90,02 \mathrm{~cm}$, respectivamente, para a altura de plantas e 54,63 e $43,16 \mathrm{~cm}$, respectivamente, para o comprimento da maior raiz (Tabela 03).

No caso da área foliar, a ausência de diferença significativa entre os métodos de propagação (Tabela 04) pode estar relacionada ao número de folhas, já que independente do diâmetro menor, o total de folhas foi muito maior nas mudas produzidas a partir de sementes quando comparadas com as estacas, isto em decorrência do aparecimento de inúmeras brotações adventícias na base como já citado, o que sem dúvida contribuiu para os resultados de massa fresca e seca das folhas (Tabela 04), já que estas são variáveis interdependentes.

Mesmo não havendo interação significativa entre substrato e método de propagação para volume, massas fresca e seca das raízes, a inexistência de diferença entre plantas produzidas por estacas e por sementes (Tabela 05) pode estar associada aos substratos, os quais sem dúvida proporcionaram, de forma homogênea, condições favoráveis ao desenvolvimento das raízes. De acordo com Hartmann et al. (2002), o sistema radicular só se desenvolve satisfatoriamente quando o substrato combina boa aeração com alta capacidade de retenção de água, boa drenagem e ausência de contaminantes.

Outro ponto relevante ao enraizamento diz respeito ao teor de hormônios endógenos. Segundo Hartmann et al. (2002), este processo é dependente de uma delicada combinação de compostos, sendo a relação entre auxinas e citocininas essencial ao desenvolvimento das raízes.

Quanto aos substratos, não foram constadas diferenças significativas entre as possiveis misturas de materiais para a variável altura de plantas, área foliar, comprimento da maior raiz, massa fresca e seca de folhas e raízes, e volume das raízes (Tabelas 03, 04 e 05). Ao se avaliar cada uma das variáveis isoladamente, foi possível constatar que o tratamento solo + Plantmax ${ }^{\circledR}$ se sobressaiu na maioria dos casos, principalmente no processo de enraizamento, já que os valores mais expressivos são encontrados para volume, comprimento, massa fresca e seca das raízes. Embora não constatadas diferenças estatísticas significativas, estes dados são semelhantes aos encontrados por Braun et al. (2010) que ao avaliarem o efeito do substrato e comprimento de estacas na produção de mudas de tomate, constataram que a mistura de solo+areia+esterco bovino e Plantmax $®$ isoladamente, proporcionaram um aumento significativo no enraizamento e desenvolvimento das mudas se comparado ao emprego de areia. Segundo estes autores isto ocorreu porque a adição de matéria orgânica ao solo ou a mistura de um material inerte como a areia a outro biológico como solo ou Plantmax® contribuiu para a melhoria das condições físicas deste, como aumento na taxa de nutrientes e da porosidade, essencial à aeração radicular, já que de forma isolada, devido à sua alta densidade (solo) ocorre maior compactação das partículas e, conseqüentemente, redução dos poros. Além disso, a utilização de areia como única fonte de substrato é limitante para as estacas herbáceas, já que ao contrário de boa parte dos materiais possui baixa retenção de umidade e nenhum nutriente (Dutra \& Kersten, 1996). 
ALAMINO, D.A. et al. Mudas de Physalis pubescens L. propagadas...

Tabela 3 - Altura média da parte aérea $(\mathrm{cm})$ e comprimento da maior raiz $(\mathrm{cm})$ em plantas de Physalis pubescens L. propagadas por diferentes métodos e substratos. UTFPR, Campus Pato Branco, 2011.

\begin{tabular}{lcc}
\hline Método de propagação & Altura média da parte aérea $(\mathrm{cm})$ & Comprimento da maior raiz (cm) \\
& & \\
\hline Sementes & $90,02 \mathrm{~b}$ & $43,16 \mathrm{~b}$ \\
Estaquia & $123,14 \mathrm{a}$ & $54,63 \mathrm{a}$ \\
\hline Substratos & $109,95^{\mathrm{ns}}$ & $47,41^{\mathrm{ns}}$ \\
\hline Solo + Areia & $108,85^{\mathrm{ns}}$ & $50,49^{\mathrm{ns}}$ \\
Solo + Vermiculita & $102,85^{\mathrm{ns}}$ & $51,49^{\mathrm{ns}}$ \\
Solo + Plantmax & $114,65^{\mathrm{ns}}$ & $48,41^{\mathrm{ns}}$ \\
Solo + Areia + Vermiculita & $96,60^{\mathrm{ns}}$ & $46,66^{\mathrm{ns}}$ \\
Solo & $28,82^{\mathrm{n}}$ & 20,38 \\
\hline CV\% & & \\
\hline
\end{tabular}

Médias seguidas por letra minúscula nas colunas não diferem entre si, pelo teste de Tukey a 5\% de significância. Dados transformados em $\sqrt{ } \mathrm{x} / 100$.

Tabela 4 - Área foliar $\left(\mathrm{cm}^{2}\right)$, massa fresca e seca das folhas em plantas de Physalis pubescens L. propagadas por diferentes métodos e substratos. UTFPR, Campus Pato Branco, 2011.

\begin{tabular}{|c|c|c|c|}
\hline Método de propagação & Área foliar $\left(\mathrm{cm}^{2}\right)$ & $\begin{array}{l}\text { Massa fresca } \\
\text { das folhas }(\mathrm{g})\end{array}$ & Massa seca das folhas $(\mathrm{g})$ \\
\hline Sementes & $1537,74^{\text {ns }}$ & $33,31^{\text {ns }}$ & $4,12^{\mathrm{ns}}$ \\
\hline Estaquia & $1530,72^{\text {ns }}$ & $33,94^{\mathrm{ns}}$ & $4,05^{\mathrm{ns}}$ \\
\hline \multicolumn{4}{|l|}{ Substratos } \\
\hline Solo + Areia & $1588,78^{\text {ns }}$ & $34,45^{\mathrm{ns}}$ & $4,21^{\mathrm{ns}}$ \\
\hline Solo + Vermiculita & $1403,82^{n s}$ & $31,30^{\mathrm{ns}}$ & $4,04^{\mathrm{ns}}$ \\
\hline Solo + Plantmax® & $1489,72^{\text {ns }}$ & $33,52^{\mathrm{ns}}$ & $4,02^{\mathrm{ns}}$ \\
\hline Solo + Areia + Vermiculita & $1465,74^{n s}$ & $32,95^{\mathrm{ns}}$ & $3,77^{\text {ns }}$ \\
\hline Solo & $1723,08^{n s}$ & $35,91^{\mathrm{ns}}$ & $4,38^{\mathrm{ns}}$ \\
\hline CV\% & 11,48 & 10,14 & 12,34 \\
\hline
\end{tabular}


ALAMINO, D.A. et al. Mudas de Physalis pubescens L. propagadas...

Tabela 5- Volume das raízes $(\mathrm{mL})$, massa fresca e seca das raízes em plantas de Physalis pubescens L. propagadas por diferentes métodos e substratos. UTFPR, Campus Pato Branco, 2011.

\begin{tabular}{|c|c|c|c|}
\hline Método de propagação & $\begin{array}{l}\text { Volume das raízes } \\
\qquad(\mathrm{mL})\end{array}$ & $\begin{array}{l}\text { Massa fresca } \\
\text { das raízes }(\mathrm{g})\end{array}$ & Massa seca das raízes $(\mathrm{g})$ \\
\hline Sementes & $278,66^{\mathrm{ns}}$ & $72,87^{\text {ns }}$ & $21,64^{\text {ns }}$ \\
\hline Estaquia & $296,66^{\mathrm{ns}}$ & $67,85^{\text {ns }}$ & $15,87^{\mathrm{ns}}$ \\
\hline \multicolumn{4}{|l|}{ Substratos } \\
\hline Solo + Areia & $249,99^{\text {ns }}$ & $51,81^{\mathrm{ns}}$ & $13,67^{\mathrm{ns}}$ \\
\hline Solo + Vermiculita & $283,33^{n s}$ & $76,96^{\mathrm{ns}}$ & $23,41^{\mathrm{ns}}$ \\
\hline Solo + Plantmax $®$ & $438,33^{n s}$ & $101,23^{n s}$ & $23,94^{\mathrm{ns}}$ \\
\hline Solo + Areia + Vermiculita & $208,33^{\mathrm{ns}}$ & $59,31^{\text {ns }}$ & $13,32^{\mathrm{ns}}$ \\
\hline Solo & $258,33^{\mathrm{ns}}$ & $62,48^{\mathrm{ns}}$ & $19,45^{\mathrm{ns}}$ \\
\hline CV\% & 34,61 & 28,52 & 31,59 \\
\hline
\end{tabular}

${ }^{\text {ns }}$ Não significativo pelo teste de Tukey a $5 \%$ de significância. Dados transformados em $\sqrt{ } \mathrm{x} / 100$.

Ainda sobre esses aspectos, Zietemann \& Roberto (2007) sugerem que a alta eficiência do substrato comercial Plantmax ${ }^{\circledR}$ sobre o enraizamento e/ou desenvolvimento de plantas se deve, além da alta concentração de matéria orgânica e porosidade, à grande quantidade de cargas iônicas e retenção de umidade satisfatória.

Resultados semelhantes aos encontrados neste trabalho também foram observados por Oliveira et al. (2003) ao avaliarem o efeito de diferentes épocas, substratos e concentrações de ácido indolbutírico no enraizamento de estacas semilenhosas de oliveira. Segundo estes autores, o desenvolvimento das estacas ocorreu com maior significância no tratamento areia + solo. Dutra \& Kersten (1996) ao testarem diferentes substratos na estaquia da ameixeira (Prunus salicina) observaram que a boa capacidade de drenagem e maior espaço poroso proporcionados pela areia e o equilíbrio entre os teores de água e ar, bem como a adequada densidade proporcionada pela vermiculita, propiciaram um elevado percentual de enraizamento.

Outro aspecto relevante quanto ao bom desempenho do substrato SP (solo + Plantmax $®$ ) diz respeito ao $\mathrm{pH}$ da mistura. Dentre os substratos testados o tratamento SP, juntamente com o SV (solo + vermiculita) foram os que apresentaram o $\mathrm{pH}$ de 5,0 e 5,6, respectivamente, faixa que segundo Kampf (2005) é a ideal para substratos utilizados em fruticultura. Além disso, pHs baixos como os das misturas favorecem a germinação de sementes e dificultam o desenvolvimento de algumas classes de microorganismos (Fachinello et al., 1995).

Outra hipótese sobre a ausência de diferença significativa entre os substratos é que estes foram compostos por uma porção de material inerte e outro biológico (solo), fazendo com que as características das misturas fossem bastante semelhan- tes entre si. Além disso, regas e adição de húmus de minhoca foram feitas de forma homogênea e no mesmo período para todos os tratamentos. Correia et al. (2001) verificaram que substratos contendo componentes orgânicos, como húmus de minhoca, em sua composição foram eficientes para a formação de porta enxertos de gravioleira em tubetes. Okumura et al. (2002) verificaram que, ao se utilizar o húmus de minhoca na proporção de $25 \%$ no substrato, excluiu a necessidade de adubação mineral. Negreiros et al. (2004) testando diferentes substratos na produção de mudas de mamoeiro grupo solo observaram que as misturas que receberam incorporação de componentes orgânicos foram as que apresentaram os maiores índices de massa seca da parte aérea, provavelmente pelo fato de terem modificado o equilíbrio composicional desses substratos, proporcionando melhores condições para a muda em relação à aeração, nutrição e sustentação.

Portanto, observa-se que as mudas possuem boa adaptabilidade quando desenvolvida em diferentes substratos, sendo a estaquia o método mais favorável se comparado à propagação por sementes em ambiente protegido, porém, como não foi definido um tipo de substrato específico, já que os mesmos não apresentaram diferença significativa entre si, fica a critério do produtor a escolha, dentre os tratamentos testados, do material mais adequado à sua estrutura de produção.

\section{CONCLUSÕES}

Pode-se concluir que a propagação por estaquia demonstra ser mais eficiente do que a propagação por sementes, na produção de mudas, o que possibilitaria ao pequeno produtor, redução de custos e tempo, já que a etapa de semeadura e desenvolvimento inicial das plântulas seria elimina- 
ALAMINO, D.A. et al. Mudas de Physalis pubescens L. propagadas...

da. Além disso, como as plantas têm um ciclo de vida produtivo de no máximo dois anos, estas, ao mesmo tempo em que produzem os frutos, poderiam servir como matrizes para a retirada das estacas, dando nova utilidade a um material que provavelmente seria futuramente descartado.

Em relação aos substratos, a ausência de diferença significativa entre as combinações de materiais empregados indica que ao serem mantidas em condições controladas e com a aplicação homogênea de adubação orgânica, as plantas respondem da mesma forma a qualquer um dos tratamentos.

\section{AGRADECIMENTOS}

Ao Conselho Nacional de Desenvolvimento Científico e Tecnológico (CNPq) pela concessão de bolsa de Mestrado e à Fundação Araucária pelo apoio financeiro através do Programa de Infraestrutura para Jovens Pesquisadores.

\section{REFERÊNCIAS}

1. BRAUN, H.; CAVATTE, P. C.; AMARAL, J. A. T.; AMARAL, J. F. T.; REIS, E. F. Produção de mudas de tomateiro por estaquia: efeito do substrato e comprimento de estacas. IDESIA, v.28, n. 1, p. 9-15, 2010.

2. CORREIA, D.; CAVALCANTI JÚNIOR, A. T.; COSTA, A. M. G. Altemativas de substratos para a formação de portaenxertos de gravioleira (Annona muricata) em tubetes. Fortaleza: EMBRAPA Agroindústria Tropical, 2001.03 p. (Comunicado Técnico, 67).

3. DUTRA, L., KERSTEN, E. Efeito do substrato e da época de coleta dos ramos no enraizamento de estacas de ameixeira (Prunus salicina Lindl). Ciência Rural, v. 26, n. 3, p. 361-366, 1996.

4. FACHINELLO, J. C.; HOFFMANN, A.; NACHTIGAL, J. C.; KERSTEN, E.; FORTES, G. R. de L. Propagação de plantas frutíferas de clima temperado. 2 ed. Pelotas: UFPel, 1995. 178p.

5. FERNANDES, C.; CORÁ, J. E. Substratos hortícolas. Revista Cultivar Hortaliças e Frutas. 10 ed., 2001 , p. $32-34$.

6. HARTMANN, H. T.; KESTER, D. E.; DAVIES JÚNIOR, F. T.; GENEVE, R. L. Plant Propagation: Principles and Practices. 7 ed. New York: Englewood Clipps, 2002. 880 p.

7. KAMPF, A. Produção de comercial de plantas ornamentais. 2 ed. Guaiba: Editora Agrolivros, 2005.256 p.

8. MALAVOLTA, E.; HAAG, H. P.; MELLO, F. A. F.; BRASIL SOBRINHO, M. O. C. Nutrição mineral e adubação de plantas cultivadas. São Paulo: Pioneira, 1974. $272 \mathrm{p}$

9. MARSCHNER, H. Mineral nutrition of higher plants. 2 ed. London: Academic Press, 1995.889 p.

10. NEGREIROS, J. R. S.; BRAGA, L. R.; ÁLVARES, V. S.; BRUCKNER, C. H. Influência de substratos na formação de porta-enxerto de gravioleira (Annona muricata L.) Ciência e Agrotecnologia, v. 28, n. 3, p. 530-536, 2004.

11. OKUMURA, H. H.; CAVALCANTI JÚNIOR, A. T.; COSTA, J. T. A.; CORREIA, D.; SILVA, L. D. Efeito dos compostos orgânicos e minerais em substratos na germinação de sementes de gravioleira var. Lisa. In: CONGRESSO BRASILEIRO DE FRUTICULTURA, p. 17. Anais. Belém: SBF, 2002.

12. OLIVEIRA, A. F.; PASQUAL. M.; CHALFUN, N. N. J.; REGINA, M. A.; RINCÓN, C. D. R. Enraizamento de estacas semilenhosas de oliveira sob efeito de diferentes épocas, substratos e concentrações de ácido indolbutírico. Ciência e Agrotecnologia., v. 27, n.1, p.117-125, 2003.

13. OLIVEIRA, A. B.; HERNANDEZ, F. F. F. Absorção de nutrientes em mudas de berinjela cultivadas em substratos alternativos. Revista Ciência Agronômica, v. 39, n. 4, p. 583-589, 2008.

14. RUFATO, L.; RUFATO, A. D. R.; SCHLEMPER, C.; LIMA, C. S. M.; KRETZSCHMAR, A. A. Aspectos técnicos da cultura da physalis. Pelotas: UDESC, 2008. 101p.

15. SCHNEIDER, E. P.; PAGOT, E.; NACHTIGAL, J. C.; BERNARDI, J. Ações para o desenvolvimento da produção orgânica de pequenas frutas na região dos Campos de Cima da Serra, RS, Brasil. Revista Brasileira de Agroecologia, v. 2, p. 245-248, 2007.

16. TAIZ, L.: ZEIGER, E. Fisiologia Vegetal. 3 ed., São Paulo: Artmed, 2004. 719 p.

17. ZIETEMANN, C.; ROBERTO, S.R. Produção de mudas de goiabeira (Psidium guajava L.) em diferentes substratos. Revista Brasileira de Fruticultura, v. 29, n. 1, p. 137-142, 2007. 